\title{
HOMENAJE AL DR. ALBERTO WAGNER DE REYNA, EXIMIO FILÓSOFO Y HUMANISTA
}

\author{
TRIBUTE TO ALBERTO WAGNER DE REYNA, DR., PHILOSOPHER AND \\ HUMANIST
}

\section{EN LOS ACANTILADOS}

Con ocasión de los 75 años de la aparición de Was ist Metaphysik (1927) de Martin Heidegger

Patrick Wagner Grau ${ }^{1}$

\section{RESUMEN}

El análisis ontológico del pensamiento de Heidegger acerca de la nada, nos lleva a considerar al acantilado, que se levanta orgulloso desde el vacío hontanar hacia el cielo, superando a la nadidad del vacío mismo. El acantilado exhibe múltiples grietas en su estructura propia y esas grietas son parte integrante de su ser. Del mismo modo, el ser del hombre se alza desde la profunda Nada trascendiéndola y elevándose hacia lo Infinito, teniendo como parte de su ser propio a las nadas (con minúscula) que pudieran equipararse con las grietas del ser. La Fe supera a la Nada (con mayúscula), integrando a las nadidades ontológicas que posibilitan así la trascendencia del hombre hacia lo supremo.

\section{Palabras clave}

Ontológico, ser, nada, trascendencia, logos

\section{ABSTRACT}

The ontological analysis of Heidegger's thought about nothing, lead us to consider the cliff, which stands proud from the void spring towards the sky, surpassing the Void of itself. The cliff shows multiple cracks in its own structure and those cracks are an integral part of his being. Similarly, the human being raises from the deep Void transcending and rising into the infinite, having as part of its own being the nothing (with small letter) that could be equated with the cracks of being. Faith beats Void (with capital letter), integrating the ontological voids and allow transcendence of man towards the supreme.

\section{Keywords}

Ontology, be, nothing, relevance, logo

Braman las olas que se rompen a los pies de los acantilados. Ellos se alzan verticales sobre el mar, ignorando la inmensidad y el movimiento de sus aguas agitadas. Para ellos solo son un vacío, al cual se asoman sus cimas. Ese hueco que duerme a su lado, hueco infinito y por encima del cual miran hacia el horizonte, que también es vacío.

El caminante -admirativo- se dice: los acantilados son de piedra, roca dura y noble; peñasco sólidos que dominan todo lo demás.

\footnotetext{
Médico internista, nefrólogo y especialista en hipertensión arterial. Doctor en Medicina por la U. Católica de Chile. Doctor en Filosofía y Especialista en temas de Bioética. Director de la Clínica Maison de Santé. Miembro de número de la Academia Nacional de Medicina. Profesor Principal de la Universidad Nacional Mayor de San Marcos, docente en la Maestría en Derecho Civil con mención en Familia de la UNIFÉ.
} 
El tiempo pasa silencioso a su vera, como el viento que silba su melodía de espanto. Ni las inclemencias de la naturaleza ni las insolencias de los hombres parecen tener asidero para hostigarlos: son los acantilados, desde siempre, en verano e invierno, de día y de noche, en un permanente ahora.

Su dimensión poderosa no es limitada por el hueco que bosteza a su lado. El hueco no los limita. El hueco -vacío- no puede limitar ni hacer nada, simplemente porque no es nada.

Aquí-en la doble negación, de que nos servimos al expresarnos en castellano- las negaciones no se compensan o anulan mutuamente, sino por lo contrario -como lo hace el griego en ciertos casos- se reiteran y confortan. La nada no es eso que llamamos nada, precisamente porque no es: (no) es el vacío que se halla más allá, en ningún lugar. Se pueden demarcar las rocas de los acantilados, pero no los términos de la nada, porque no tienen términos. No es dable establecer una relación con ella por inasible, indefinible, impensable -salvo como negación.

Interviene ahora un nuevo elemento: el pensar. El logos, en su intento de captar lo inasible, lo determina como una negación -acción lógica-, en cuanto que es la negación más absoluta de aquello que es. El logos solo nos dice que ella no es, señalándola como lo que queda fuera, cuando se piensa el ser, pero no atañe -toca- a la nada misma. La nada no nace de la negación; pues negación únicamente hay cuando el logos se mete -con escasa fortuna- con la nada, a ésta habrá que llamarla pre-lógica, o preconceptual, esto es: anterior a toda imaginación o manipulación mental. <La nada es más originaria que el no y la negación $>$ nos recuerda Heidegger.

Los acantilados nos hacen comprobar que más allá de ellos no hay nada, es decir "solo" lo totalmente diferente, ni siquiera opuesto (porque oponerse o ser opuesto ya sería una acción -o pasión- que implica ser): la incomprensible vacuidad. Y por ello cuando el hombre la piensa, o trata de formular sentencias, coherentes sobre la nada, se enreda en contradicciones y paradojas. Desde la roca firme no se ve la nada, simplemente está allí -no estándolo- en su opresora ausencia.

Hegel, que parte del pensar y está preso en él, ante la imposibilidad de aplicar un atributo o una determinación -Bestimmung- a la nada, así como tampoco lo puede hacer al ser en sí, concluye que la pura nada y el puro ser son lo mismo. Ello es evidente para quien se mueve en el plano lógico, para quien el logos es personaje en el drama, que llena toda la escena, y no solo apuntador o instrumento -es cierto que implicado- para ver lo que ocurre en ella. Pero, como hemos advertido, la diferencia -radica, total, absoluta- entre lo que no es nada - aquí sí doble negación (=algo) y la nada se encuentra en ámbito anterior a lo lógico.

El logos tiene por función pensar lo que es, es decir los entes, y a través de estos pensar el ser, a lo que hace que los entes sean; y así acontece en el logos la manifestación del ser. Lo lógico -pese a todos los recaudos mentales para evitar lo inevitable- asimila, en la práctica del pensar, la nada a los entes, la trata como una entidad a la cual la ausencia de ser hace que sea lo que es (no es). No puede hacerlo de otro modo: el logos todo lo ve necesariamente bajo la prisma del ser. Y dos vacíos -el puro ser, la pura nada- son idénticos.

¿Pero cómo enfocar entonces a la nada? Los hombres solo podemos hacerlo -como nos consta- con el instrumento del logos: pensándola; y entonces caemos en la paradoja.

¿No hay otra manera? Sí. Cuando al pensar la nada tenemos conciencia de su asimilación subrepticia al ser, por el pensamiento mismo. La re-flexión, en que el pensar vuelve sobre sí mismo para criticarse, para censurar esta asimilación abusiva pero ineludible, nos abre un camino para salir de ella. La reflexión, por más crítica que sea, es siempre lógica y nunca logrará plenamente su intento; sin embargo, por lo menos señalará en qué dirección se encuentra la salida de la paradoja, la boca de la cueva.

La nada no es ni un punto, ni un ámbito; no es un modo defectivo o negativo de ser, como 
si fuera su contrapartida o su sombra; ni el resultado de un acto lógico -eso es el concepto de la nada-, no es nada de eso o cuanto se puede imaginar o concebir. Pero si bien no está en ninguna parte, ni sobre todo en el pensar, se puede decir que gracias a este-el pensar- la sabemos allende el propio pensar.

La conciencia de la paradoja no resuelve la paradoja, pero como resulta nos queda un conocimiento de la causa de la paradoja y con ello de nuestra limitación e ignorancia frente a la nada. Sabemos ahora hacia dónde dirigir nuestra escrutadora mirada: hacia el vacío, hacia el vacío en que hemos, pensándola, localizado la a-topía -ausencia de lugar- de la nada. La nada no ha lugar.

Para nuestra sorpresa, afirma Heidegger $<$ Im Sein des Seienden geschiebt das Nichten des Nichts>. < En el ser del ente acontece el anonadar de la nada $>$. De la paradoja hemos caído en la perplejidad. Sin embargo, lo que no es asequible al logos -la nada- lo encontramos -según Heidegger- en la angustia. Para comprender debidamente esta afirmación, $y$ en general el pensamiento del filósofo, es necesario tener presente uno de los momentos básicos de este: la diferencia ontológica. Es decir la diferencia fundamental entre ser $y$ ente: el ser es lo que hace que el ente sea, que sea, que sea lo que precisamente es.

La nada anonada y este anonadar se hace presente en la diferencia ontológica, o mejor dicho: la diferencia entre lo ontológico (el ser) y lo óntico (el ente) radica en el anonadar, como testigo y revelador del acontecer del uno en el otro. Del ser al entre hay el trecho del anonadar. El ser transciende a la nada y ésta -la nada- nada puede contra él; en cambio el ente (que es porque el ser hace que sea) está expuesto a la nada, en que se sostiene: se halla en su mismo nivel y puede desaparecer, ser aniquilado por ella. No en vano llama Heidegger a la nada <das Andere zum Seienden $><$ lo otro con respeto al ente $>$. El anonadar es pre-ontológico, el aniquilar acontece en el plano óntico.

¿Es el anonadar una acción? Dijimos que el vacío no puede hacer nada y sin embargo llama, desde el fondo de su ausencia y hacia a él: el anonadar es hacer nada. ¿Es lo mismo "hacer nada" que "no hacer nada"? Lo primero sugiere un des-hacer, una acción con signo negativo, la destrucción de al -hacer un vació-; lo otro, una inacción, lo contrario de hacer, quietud. El anonadar participa de ambos extremos y no es ninguno de ellos, porque se encuentra allende estos conceptos... como la nada. Y, con todo, el anonadar se manifiesta en la angustia. Hay aquí una ambigüedad e incerteza, una lejanía de la inmediatez, que atrae como el vació, al cual se abren los acantilados, pero que también rechaza, en el vértigo, por su radical extrañeza y amenazante peligrosidad.

La angustia -momento óntico pero de trascendencia ontológica- es contradictoria, porque el anonadar -pre-ontológico- es un beim -lieb- que no tiene relación alguna con casa (Heim)-, inhóspito, y por ello siniestro, atopos, sin lugar.

Mientras que el habla -logos-, es la del ser. En la angustia estamos frente a la prístina "indomiciliación", de la cual están ausentes tanto el domicilio - el ser-como el domiciliante -el logos-.

El caminante -entre perplejo y curioso- se acerca a los acantilados, que se atreven a hollarlos, se da cuenta que no son raras las grietas en ellos, y que estas pueden ampliarse hasta provocar derrumbes. La mole de piedra, que en sí es sólida e inconmovible, presenta en veces fallas, en que se infiltran sutilmente el vacío, la nada. La grieta, ella sí, es una distancia entre dos cuerpos, y puede ser medida y traspuesta. Esta falla es vecina del ente y hay quienes la tratan y utilizan como si fuera un ente, un ente virtual. Es posible decir dónde está, ubicarla, representarla, aplicarle los grilletes del algoritmo, hacerla objeto de una ciencia, manipularla... Es un espacio, evidentemente vacío, pero con sus dimensiones, perceptible y pensable. No obstante, su filiación en la nada es innegable, y de allí viene la dificultad de reconocer su pertenencia al plano óntico. Y tan es así que nadie menos que Kant considera al espacio en el ámbito de la estética trascendental. 
La nada resulta así ambivalente: no es solo lo opuesto al ser -y en puridad indiferenciable de él-sino que también lo es al ente. Se revela como perteneciente al ser del ente, en cuanto que en la entraña del ser sale a luz el ente, sosteniéndose en la nada, al oponerse a ella. Esta exposición a la nada, que atañe -en su propio ser-al ente, hace que la vieja sentencia ex nihilo nihil fit adquiera el sentido de ex nihilo omne ens qua ens fit.

Estamos ante la crisis del pensar, cuando nos arriesgamos a hollar esos acantilados, crisis que Heidegger asumirá, poniéndola de manifiesto. No solo hay grietas -con estirpe de nada- en la roca del ente, sino que la nadidad es condición del ente: el anonadar, al acontecer en el ser del ente, hace -como vimos -que el ente sea el ente que es. Con ello se establece no solo la finitud del ente sino del ser, que requiere de la "concurrencia" del anonadar para que sea el ente, de modo que < das Sein selbst im Wesen endlich ist $><e l$ ser mismo es en (su) esencia finito $>y$ "solo se manifiesta en la trascendencia del existir -Dasein- expuesto a la nada". Y esta trascendencia es el ser-en-el-mundo.

Heidegger la llama Sorge, cura (en latín), cuidado, un cuidar del mundo y cuidarse de él, en que se enfrenta con la muerte y la vive. Vivir es vivir muriendo, dice Quevedo; el hombre al dirigirse hacia la muerte, asume su finitud, su finita temporalidad.

Ante la apertura de la nada al hombre en la angustia, ante la "concurrencia" de ella en el anonadar- a que el ente sea, el ser se hace cuestionable, se convierte a su vez en pregunta. No únicamente como objeto de una pregunta tradicional de la filosofía -la pregunta metafísica-, sino intrínsecamente en su posibilidad de proporcionar una respuesta por la inherencia de la nada en él. Sin llegar a verificarse la metáfora de Paul Valéry "rocher d'air pur", ni convenir con la vulgaridad de que "el ente está mechado de nada", el acantilado ya no se yergue -a nuestros ojos- solitario $e$ inmune a todos los embates, el ser pierde su carácter de absoluto, es finito, y es respecto a algo, algo que es precisamente la nada.

Y Heidegger, en el breve proemio (1949) a "Vom Wesen des Grundes", nos dice: "La nada es el $<$ no $>$ del ente y así el ser percibido -erfahrene Sein- desde el ente. La diferencia ontológica es el no entre el ente y el ser". Y nos pone en guardia para que no entendamos este "no" como un nihil negativum y la diferencia como un ens rationis, producto de una distinción del intelecto.

Frente a los farellones, que se imponían sólidos, inmutables y soberanos y que suscitan nuestro asombro -condición de todo filosofarnos hallamos ahora desamparados, sumidos en confusión: nuestro preguntar ingenuo (es decir: originariamente libre, sin pre-supuestos) ha recibido una respuesta que a su vez es una pregunta. Ello en sí no sería nugatorio, si no estuviera cargada - como lo está- de un lastre, el lastre impalpable de la nada, que de cuestionada- aparece como cuestionante, poniendo en cuestión al ser. El asombro se convierte en pasmo. El empuje metafísico sofoca. La angustia ante la nada se abisma. Ya no atraen nuestras miradas los acantilados; contemplamos el abismo amenazante que se abre a nuestros pies.

Recapitulemos -a riesgo de ser esquemáticos y de incurrir en simplificaciones desfiguranteslos pasos de nuestro discurso. En virtud de la diferencia ontológica, hemos colocado de un lado al ser (cuyo ámbito llamado ontológico) y del otro a los entes (que pertenecen al ámbito óntico). Frente a ambos: la nada, lo <otro> respecto a los entes.

¿Es ella, pues, también lo < otro > en vista del ser? Sin duda, pero con una advertencia: en él-el ser-acontece el anonadar de la nada. La nada está (es decir: no está) más allá del ser, un más allá que tiene que ver con él, pues el anonadar, su "acción" (no acción) ocurre precisamente en el ser, en cuanto los entes se fundamentan en él. La nada se halla sí implicada en el ser (implicada en el doble sentido de esta palabra: obstar, impedir, de un lado; llevar en sí, significar, del otro). Y habría que subrayar: más implicada en el ser que con los entes - si caben aquí estas expresiones - pues frente a éstos no es nada más que lo <otro>, en cambio que con el ser se "identifica" como lo totalmente diferente. 
Estas aporías hacen sospechar al filósofo mejicano Agustín Basave que en la raíz del ser yace una instancia más profunda, que él llama la habencia. Sería ella un fundamento pre-ontológico y ante-nádico -permítaseme el vocablo - en el cual concurren ser y nada. Y el discurso de Heidegger parece darle la razón: este emplea el término es gibt $<$ hay $>$, que de suyo conviene a los entes, también refiriéndose a la nada. Das Sein <ist> "so wenig wie das Nichts". Aber es gibt beides". Tan poco <es> el ser como la nada. Pero hay ambos). Haber se aplica, en efecto, a todo: hay ser, hay pan, hay alegría, no hay nada, no hay nadie... Ser resultaría así uno de los modos de habencia.

¿Pero habríamos avanzado algo con esto? ¿No se trasladaría -por una trasmutación de palabras- simplemente el problema con todas sus dificultades a un plano que se supone anterior? Por cierto que el sentido de ser $y$ del haber no coinciden en el manejo del habla. El uno es determinado, como si tocara su objeto por dentro; el otro, impreciso, como si lo abordara por fuera. Pero ambos apuntan a lo mismo: hacia algo, que, desde el fondo de nosotros mismos, nos interpela por su presencia... o ausencia.

El Dasein trasciende al ente hacia el mundo (lo que equivale a: en el Dasein trasciende el ente hacia el mundo), de suerte que la trascendencia es el ser-en-e-mundo. Pero nos advierte Heidegger que con esta interpretación ontológica del existir como ser-en-el-mundo no queda decidido nada -ni positiva ni negativamente- sobre un posible ser-haciaDios, aun que sí ganado -añade-el terreno desde el cual se puede preguntar en relación a qué ente está ontológicamente condicionada la relación con Dios.

Para Heidegger solo se puede pensar en lo sagrado a partir de la verdad del ser y solo a partir de la esencia de lo sagrado es pensable la esencia de la divinidad, y solo a la luz de ella se puede pensar a Dios ( $y$, dicho sea de paso, a "los dioses").

La teodicea se reduciría entonces a ser un capítulo de la "ciencia" de la trascendencia finita del existir a la cual hallaría referida, es decir a una fenomenología del ser -frentea-Dios. ¿No hay otra posibilidad para ella? ¿Y, si ésta fuera factible, a partir de la propia reflexión de Heidegger aunque a riesgo de rebasar el método fenomenológico?

Johannes Baptist Lotz ha elaborado un paralelo entre Santo Tomás y Heidegger en lo que concierne a la diferencia ontológica y mostrado sorprendentes coincidencias entre el pensar de uno y otro. Según este eminente jesuita discípulo de Heidegger, el Aquinate concibe a Dios no como ente sino como ser. Apoya su interpretación en pertinentes citas. Me parece que ésta, sin embargo, se basa en una traducción o intelección demasiado estrecha del término "ese" -que no es unívocoque mal se compadece con multitud de textos en que Dios es entendido como ente supremo, simplísimo, subsistente, increado.

Pero, precisamente, el que Dios sea, como dice Santo Tomás y nos recuerda Lotz, "ens per essentiam", abre una perspectiva que merece ser ahondada.

El meollo del tema en discusión nos lo presenta esta frase: "la pregunta acerca de la esencia del fundamento -des Grundesdeviene el problema de la trascendencia". Y -nos adelanta Heidegger- la trascendencia del existir es el fundamento de la diferencia ontológica. Es decir que esta fundamental diferencia reposa en un ente -el Dasein- en cuanto que trasciende hacia el mundo, en tanto que es ser-en-el-mundo.

Indudablemente el ser no es un "objeto" frente al existir-dado que este es- pero la diferencia ontológica resulta aquí ser en vista de... con respecto a... un ente -el existir- que si bien es trascendente es también determinado y finito, $y$ no el ente en su totalidad (das Seiende im Ganzen), aunque en su relatividad lo abarque.

Según Heidegger el existir -Dasein- no es un ente entre otros, que gracias a su facticidad puede ser-en-el-mundo, sino por lo contrario. El hablar sobre el ser-en-el-mundo tiene el carácter de una <tesis ontológica $>$ según la cual puede el Dasein ser existente. Dicho de otro modo: no se está en el mundo porque se 
es hombre sino se es hombre porque se está en el mundo.

Cabe aquí preguntarse cómo una constitución fundamental (Grundverfassung) que es el ser de un ente-aunque trascendente-de facticidad limitada y finita, pueda asumir el carácter de principio total y general (uberbaupt). La fundamentación de la diferencia ontológica en la trascendencia del ser-en-el-mundo se hallaría así puesta en tela de juicio en su alcance irrestricto.

La pregunta por el fundamento no tocaría así verdadera y absolutamente fondo (el fondo del fondo) sino que iría al trasfondo del existir. En efecto, la dicha pregunta como explica Heidegger en Vom Wesen des Grundes- se dirige a mostrar la "libertad como libertad hacia el fundamento", que se revelaría ser la trascendencia del huma existir. Sin perjuicio de la importancia fundamental de la libertad para el ser-en-el-mundo ¿no habría de buscarse el fundamento absoluto por otro camino?

Heidegger cita e interpreta en Vom Wesen des Grundes el principium rationis de Leibniz, el axioma que dice: nibil ese, sine rationis, sed nullum effectum ese absque causa. Es este un principio absoluto, sin referencia al exisitr, al ser-en-el-mundo, y por lo tanto ontológicamente anterior a él, que trasciende totalmente -im Ganzen- lo que es, que radicalmente "da razón"-como primera (última) Begrundung (fundamentación)- de la "Allbeit des Seienden".

Llegaríamos así por la pregunta por la <causa $=$ fundamentación = razón de ser $>$ a la distinción de ens creatum y ens increatum -que no deja de tener presencia Heidegger en varios lugares de su obra- y con ello a Dios. El primero es lo fundado, este lo fundante. Es este caudal (de todo ente y razón (del ser). Causa sui y ultima ratio. No intentaremos en este lugar desarrollar una teodicea -inspirada en el andamiento del pensar y la terminología de Heidegger- pero sí observar, brevemente, algunos aspectos relevantes según los cuales Dios puede ser entendido en esta perspectiva.
Por lo pronto, la "relación" de Dios con la nada: no hay nada de común -KOINON- entre Él y la nada (como entre ella y el ser y los entes creados). Una "relación" entre ambos solo puede, pues entenderse como derivada de la intervención de logos, que nos la presenta como un ens rationis. La creación exnihilo no significa intervención de la nada sino ausencia $(<$ no $>$ ) de toda participación extraña en la obra creadora. La nada no es, porque Dios no le ha dado ser. La nada no es -ni no es-frente a Dios: el vocablo "ser", en rigor, no le es aplicable ni positivamente ni negativamente, solo lo hace el logos como una manera de hablar.

Dado que "la nada anonada en el ser del ente" y que "la nada es el no entre el ser y el ente", hay una vinculación íntima entre ella y la diferencia ontológica: la nada es el hiato en que se funda la diferencia ontológica. Dada, de otro lado, la absoluta diferencia entre Dios y la nada, resulta que carece de sentido hablar aquí, es decir con referencia a Dios, de diferencia ontológica. Así como los escolásticos no distinguen en Dios esencia y existencia, así también, el ens no es diferente del esse en Él.

Lo óntico y lo ontológico se integran en Él en uno: en el condicionamiento ontológico no hay escisión entre condicionante y condicionado. (Esta escisión es propia de lo creado, que es a lo cual se refiere el discurso de Heidegger sobre el ser y la nada). En Dios, ser y ente son lo mismo; es ésta una de las manifestaciones de su simplicidad en su totalidad. Su identidad y mismidad no depende de algo "externo" a Él, como sería el ser-en-el-mundo o la nada. En su trascendencia se basta a sí mismo.

$\mathrm{El}$ ente (finito y creado), que se encuentra quebrado en su multiplicidad - como nos lo recuerda Lotz-, remite hacia una pura unidad, y a través de la finitud brilla la encubierta infinitud. Aquí el "in" no significa una mera negación (o ausencia de algo) sino tiene una connotación positiva de "superación" radical, de sublimidad (estar incomparablemente por encima de otros). Dios es así in-finito en su trascendencia. No hay "nadidad" (Nichtigkeit) en ella: la palabra "ser" -al referirse a Dios- no debe ser cruzada al escribirse, como lo hace 
Heidegger, para indicar la no autonomía del ser que se sostiene en la nada.

Al trascender las cosas, que queda Dios en sí mismo porque no tiene límites: el concepto de "límite" carece de sentido en este contexto. Está en todos los entes como una presencia implícita y sustentadora, como trasfondo, que fundamenta en su fundamental diferencia. Dios no ex-siste, pues solo el hombre existe, esto es sale fuera de sí: Dios insiste -lo subrayaba siempre el P. Ismael Quiles S.J.-, trasciende hacia sí mismo, y de este modo subsiste, es subsistente.

Uno de los modos del trascender y de sustentar es el crear y mantener en el ser, por el cual el ens creatum se halla referido a su Creado. Este no se aparta de sí al trascender: por su inmanencia, queda en sí, y sin embargo va más allá de sí, en cuanto es ese trasfondo en que radica lo creado. La creatura, en cambio, es expuesta, se abre -por la creación misma- a la trascendencia.

Esta apertura, que compromete al hombre porque lo lleva a buscar en el hontanar de sí mismo a Quien lo trasciende, es el ser -haciaDios (para preguntarse por la cual, nos dice Heidegger, que es necesario que un "suficiente concepto del Dasein" sea logrado mediante la aclaración de la trascendencia).

En el existir -en cuando ens creatum-, la trascendencia del ser-en-el-mundo supone una originaria trascendencia, un ser -hacia- Dios, que la posibilita (aunque no sea ello siempre manifiesto) y que es fundamentalmente un ser-desde- Dios. Y así como asistimos a un <olvido del ser> (Seinsvergessenheit) que es lo mismo que el olvido de la diferencia ontológica -propio de nuestra Metafísica, y señalado por Heidegger repetidas veces-, no es menos notorio un <olvido de Dios>, como una de las más perversas manifestaciones del nihilismo reinante y vigorosamente denunciado por ese pensador.

Llegados a este punto, cabe formular una pregunta fundamental: ¿Allende el ser "emparentado" con la esencia de la nada (que es el ser de los entes creados) y el Ser absoluto (en que el ente se identifica con su ser) habría -por ventura- una instancia "común" o "superior" o más "profunda", algo así como una prístina habencia, que a ambos involucrara y fundamentara?

El Ser absoluto no puede ser pensado como excluyendo nada -solo a la nada-, está, pues, presente en el ente en su totalidad, trascendiéndolo, en el acto de creación y de mantenimiento en el ser. Pero, de otro lado, hay una diferencia radical entre el Ser absoluto $y$ fundante y el ser finito $y$ fundado. ¿Son estos extremos conciliables? La solución de tal aporía nos la da el Aquinate: "omne ens, inquantum habet ese, sit ei (Deo) simile". Esta similitud es -como lo ha desarrollado con acierto Przywara- una analogía. El ser de lo creado es analogon del ese subsistens.

No hay pues una instancia "más allá" que abrace la diferencia ontológica de lo creado y la in-diferencia ontológica de lo divino. Sin embargo -dado que media entre ellas el acto de la creación- la analogía se revela como un reflejo, un reflejo por el cual lo imperfecto es imagen de los perfecto: la creación entera se nos presenta como imago Dei, referida a Él, en-causada en Él.

Esta deductio a Deo, esta dependencia fundamental del hombre -imagen, bíblicamente acreditada, de Dios-, se halla a la base de un acontecer existencial, de una Stimmung -disposición o temple de ánimoque interioriza nuestro ser -hacia- Dios. Así como la angustia nos revela la nada, así aquella nos "domicilia" en la entrega a Dios. Es la confianza. A la luz de ella, la nada pierde su inmediatez y el Dasein descubre, dentro de la limitación de su trascendencia al mundo, una nueva dimensión, anagógica y exaltante, que lo abre hacia lo infinito, que es el fundamento último y más profundo de su ser.

En la angustia ha tocado el hombre fondo en el abismo de la nada, se ha rendido al confuso anonimato de la retracción del ente en su totalidad. Por la confianza, vence a la angustia y la trueca en empuje y brío, seguro de su hontanar y meta: la plenitud del ser. Por eso la confianza, en último término está siempre 
referida a Dios, es confianza en Él. Solo Dios es confiable.

Merece observarse más de cerca esta "virtud": en griego se dice DYNAMIS -fuerza-, que está siempre a punto de saltar, preparada a la acción y atraída por ella, pero que no se manifiesta todavía, potencia que aún no se ha convertido en acto, reteniéndose en un temple de ánimo. Su nombre - "confianza" - comienza por una preposición que le sirve de prefijo con- que señala cierta pluralidad, en este caso reciprocidad, un estar juntos, en compañía. El otro componente de su nombre deriva de fiar, de fidere, tener fe. Confiar significa tener $\mathrm{fe}$, que cuando es recíproca pone al hombre "en confianza", y se establece una fidelidad correspondida. Cuando se halla alguien en confianza con otra persona se establece un ambiente de intimidad y se puede prescindir de rodeos, ir de frente al grano, dejar de fingir, confesar flaqueza... El peso del término está en "fe", que es creer sin haber visto, en tener por cierto lo que no nos consta, en mérito de la palabra o la seguridad que nos da otro. Confianza es así una intimidad apoyada en la veracidad (y ésta en la verdad), en el creíble testimonio ajeno, precisamente de aquel en que confiamos.

Hay, sin embargo, un elemento más en la confianza: es ella prospectiva, en vista de algo que no ha acontecido aún, de algo que se espera. ("Yo confío en que mi amigo vendrá". Confío porque mi amigo es fiel, digno de fe, me lo prometido y no me dejará abandonado). De allí que el elemento "esperanza" adquiera un peso preponderante en la confianza. Santo Tomás la define: "una esperanza fortificada por una sólida convicción", convicción ésta que es evidentemente la fe. El carácter de DYNAMIS se confirma en ella: la fuerza encaminada, segura de sí misma, a punto de desencadenarse... pues, cuando se produzca aquello que confiamos ha de realizarse, ya no tiene sentido -por falta de objeto- hablar de fe y esperanza. Es, entonces, el campo de la satisfacción, posesión, beatitudo.

Pero esto no es todo: en la confianza el acento se pone más en el quién que en el qué, en la persona en que tenemos confianza que en aquello que confiamos ocurrirá. (Si confío en un administrado (quién), le dejo latitud para que ejerza su oficio, y no me preocupo de cada una de las operaciones que emprenda (qué). Y, cuando confío en que el coche llegará a su hora (qué), siempre hay en una u otra forma una persona en quien -quizás vagamentedepósito mi confianza: el chofer, la agencia de taxis, etc.)

La confianza es una DYNAMIS en reposo, como la angustia que también es una Ruhe tranquilidad, descanso- aunque de contrario signo. Si la angustia es una ausencia de apoyo, que sin embargo pesa y oprime, es la confianza una liberación, que se basa en una sólida convicción y que confiere seguridad.

Ambas producen una indiferencia (ataraxia o quietud) frente a las circunstancia, aquélla por "presencia" de la nada, ésta por la "intimidad" con Dios.

La vivencia existencial de la superación de la angustia por la confianza es ilustrada -en el plano ético-religioso- por el salmo 129: De profundis. Desde el profundo abismo, de la miseria de no tener apoyo (falta de sostén, como es el sostenerse en la nada), por la deprecación y la esperanza, el hombre logra apoyo en la palabra de Dios. Gracias a la misericordia divina -que es una forma de la trascendencia del Creado- llega a la redención en que encuentra la quietud en Él.

Es indudable que la estancia sobre los farellones tiene sus riesgos. Esas andanzas por las cumbres, que bordean abismos, son siempre una aventura. Acecha el peligro de caer en ellos $y$ en la profundidad de lo insondable confundir verdades y errores pues -como nos recuerda Heidegger- moran allí, en la más cercana vecindad, los unos con los otros. El viandante se sabe en terreno inseguro. La firmeza de la roca no corresponde a su apariencia, y pronto se sospecha que disimule cuevas y oquedades, si no despeñaderos. Y sin embargo, allí se alzan soberanos los acantilados, en la soberbia de su solidez. El hombre no sabe qué pensar de esos montes: a ratos, parecen espejismos, como si surgieran del mar. ¿Son tan insensibles, como pensábamos, a las olas que en ellos se rompen 
y revientan? Las preguntas se agolpan, $y$ llevan a menudo a callejones sin salida, mientras que el vértigo acecha y amenaza surgir de ninguna parte. En suma: el transitar por aquellos empinados riscos es tan peligroso como la ineludible tarea que asume el hombre de enfrentarse al ser.

El hombre (según Kant, metafísico por naturaleza) es -nos dice Heidegger-el pastor o guardián del ser, y precisamente su existencia (con)siste en el cuidado -cura- de su ser en el mundo. El hombre es el curador del ser. Pero de otro lado, es el lugarteniente de la nada, en cuanto mantiene abierto el lugar a lo "otro del ente" (la nada), de modo que en esta apertura pueda darse el ser. iCurioso pastor este que también trabaja para el lobo! (¿No podría colarse por el resquicio de esta ambigüedad del existir cierta coloración ética en la filosofía "amoral" de Heidegger?). En suma: no olvidemos que, guardado por el hombre, el ser (creado) solo puede darse desde la nada, y que este participa así en esta "complicidad" entre el ser y la nada.

La finitud del hombre, fundada en ésta, se revela -como sabemos- en la angustia (en que afronta a la nada), determina, dentro de la ataraxia, una inquietud, un preguntar y preguntarse acerca de sí mismo, por el mundo, por el trasfondo de las cosas, por el ser, por la nada; en este desasosegado sosiego -pues la quietud de la angustia es quietud de signo negativo-, el vértigo lo coge, amenaza con despeñarlo, el abismo lo llama y lleva al caminante a levantar los ojos en busca de algún sostén (Halt) confiable que lo remedie en su desamparo, pues comprende que las rosas son de dudosa reciedumbre. Y así descubre la amplitud del cielo, de esa bóveda de evidente inmensidad.

A través de la trascendencia del ser-en-elmundo percibe la trascendencia infinita, que lo envuelve, habita y traspone. Las contingencias terrenas, la "identidad" contradictoria de grietas y peñas, abismos y cumbres, se inscriben en una dimensión olvidada por la cura, preocupada de lo inmediato y urgente. La caliginosa angustia cede ante la irrupción de la luminosa confianza. El ser -hacia (desde)Dios libera al hombre, le abre un horizonte, que contempla desde su risco, ya no de vacuidad sino de plenitud, que lo fija en él pero a la vez lo coloca en la inmensidad absoluta y -como promesa- lo expone y entrega a ella.

Desde los acantilados -para los que saben ver más allá de sus contornos- el panorama de cielo y tierra cobra un sentido, y la verdad del ser, en todas sus dimensiones, puede ser vivida y aceptada. La brisa de eternidad, leve y serena, despeja la pesantez de la agitación de los tiempos. El caminante, que se ha aventurado por esos parajes $y$ escucha el rumor del silencio, puede entonces preguntarse, como lo hace Heidegger al final de su camino por el campo: "¿Habla el alma? ¿Habla el mundo? ¿Habla Dios?

La respuesta está en la confianza. 


\section{REFERENCIAS}

Heidegger, M. (1960) Sein und Zeit, Ed.

Heidegger, M. (1944) Carta sobre el Humanismo, Trad. de Alberto Wagner de Reyna, Belo Horizonte.

Pogeler, O. y Heidegger, M. (1973) Su filosofía signo de nuestro tiempo, Múnich.

Alberto Wagner de Reyna (1949) La Ontología fundamental de Heidegger, Lima.

Alberto Wagner de Reyna (1954) Sobre el nihilismo, Santiago.

Alberto Wagner de Reyna (1955) Hacía más allá de los linderos, Santiago.

Tristan d'Athayde (1955) El pensamiento de la Existencia de Martin Heidegger, Sao Paulo.

Alberto Wagner de Reyna. (1959) Conversaciones en torno a Heidegger, Santiago.

Juan de Dios Vial L. (1964) Heidegger: el hombre y su pensamiento, Santiago.

Agustín Basave (1986) Estudios sobre la Habencia, México. 